\title{
CT HYPODENSITY ON CEREBRAL WHITE MATTER IN WILSON'S DISEASE
}

\author{
LAURA B. JARDIM * — ANÍBAL CARNEIRO ** — SUZANA HANSEL ** \\ CARLOS R. M. RIEDER ** - ROBERTO GIUGLIANI ***
}

\begin{abstract}
SUMMARY - Wilson's disease in an autosomal recessive disorder of copper metabolism where systemic manifestations are secondary to thei accumulation of copper in hepatic, nervous and other tissues. In CNS, the structural lesions most commonly found by CT scan are ventricular dilatation, cortical atrophy, basal ganglia hyperdensities, and brainstem and cerebellar atrophy. Degenerative changes of cerebral white matter seen on early anatomo-pa thologic studies, but were almost never found on CT scan from recently described patients. We report a case of Wilson's disease with an unusually rapid deterioration where asymmetric low-densities in the subcortical white matter were disclosed by CT scan.
\end{abstract}

Hipodensidade tomognúáíca em substância branca na doença de Wilson.

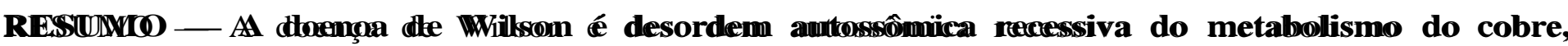

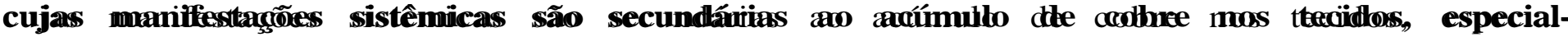
mente no fígado e no SNC. Neste, as llescéess estnutuurais mais comumente encontradas pela TC são: dilatação ventricular, atrofia cortical, hiperdensiddiddes dos núcleoss dan başe ei atrofia

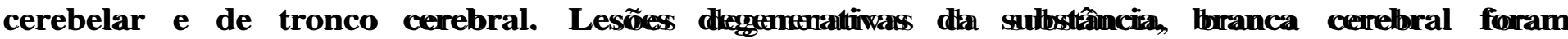

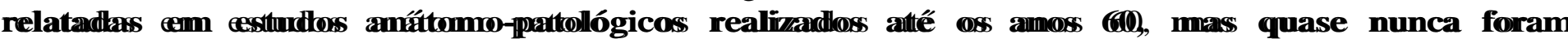

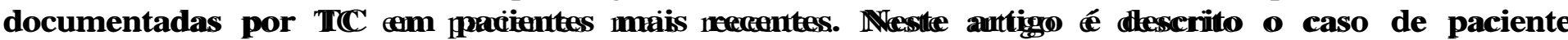
com doemça dhe Willstom, dhe nápida deterioração, no qual a TC mostrou hipodensidades assimétricas na ssubstâmcia bramea ssubcontitical.

Wilson's disease (WD), or hepatolenticular, degeneration^ ${ }^{\wedge}$ is an autosomal recessive disorder of copper metabolism, where the biliary excretion and hepatic incorporation of this metal into ceruloplasmin are both severely impaired. Although it was described as a clinical entity by Wilson in 1912, the basic lesion underlying these two disturbances is not yet known. Systemic manifestations are secondary to the accumulation of copper in the organism: defective biliary excretion leads to liver deposits with hepatic damage and subsequent overflow to the brain (causing some extrapyramidal syndromes), to the cornea (causing Kayser-Fleischer rings), and to the kidneys (causing renal tubular damage and osteoporosis) ${ }^{4}$ An effective treatment was proposed in 1956, based on the long-life use of D-penicilamine. WD has been recently mapped to the long arm of chromosome $13($ q14.1), and it seems that a tight linkage exists between the WD locus and the esterase D locus. Restriction fragment length polymorfism analysis could distinguish carriers from affected patients 5. This will allow the performance of preclinical diagnosis, and the earlier start of the therapy. Patients with WD show a variety of signs and symptoms, but the hepatic and the neurologic forms are predominant 3,4,10. Liver disease can appear beyond 6 years, but the mean age of onset is 9.4 years 4,io. The neurologic form usually starts later: the mean age of onset is 15 years 10. Tremor, dysarthria and incoordination are the

Medical Genetics Unit and Neurologic Service, Clinical Hospital of Porto Alegre (Brasil): * M.D., Neurologist and Clinical Geneticist; M.D., Neurologist; *** M.D., Ph. D., Clinical Geneticist.

Dra. Laura B. Jardim - Unidade de Genética Médica, Hospital de Clínicas de Porto Alegre Rua Ramiro Barcelos 2350 - 90210 Porto Alegre RS - Brasil 
most frequent neurologic signs 1.4. Some authors think that tremor plus dysarthria and rigidity plus disorders of posture are two separate syndromes with different prognosis on treated cases 3. However, the former signs are often followed by the others, and a pseudobulbar palsy may develop at any time and is the cause of death in many untreated cases. On the psychiatric side, depression and personality changes seem to be common as first symptoms, but deterioration of intellectual functions usually comes later is. The classic diagnostic features are the Kayser-Fleischer rings, low plasma ceruloplasmin, increased plasma nonceruloplasmin copper and increased urinary copper excretion. They are found in all patients with neurologic manifestations, but in only 70 to 90 percent of those with only liver manifestations. In these cases, hepatic biopsy with copper content determination is useful, but the most definitive test is the incorporation of $64_{\mathrm{c} \text { u }}$ or $67_{\mathrm{c} \text { u }}$ into ceruloplasmin 2,4 .

Regarding the CNS, the structural lesions most commonly found by CT scan are ventricular dilatation, cortical atrophy, basal ganglia hyperdensity, brainstem atrophy and posterior fossa atrophy 13,15. Degenerative changes of cerebral white matter were described on early anatomo-pathologic reports $n$. Similar findings on CT scan of living patients, on recent years, seem to be very rare. We describe here a case of WD with rapid neurologic progression where the $C T$ scan disclosed asymmetric low-densities in the subcortical white matter.

\section{CASE REPORT}

SARG is a black male whose first symptoms were clumsiness, dysarthria, tremor of extremities and difficulty on) walking at the age of 15 years. He was first examined one year after the onset, and there were Kayser-Fleischer rings in both corneas, diffuse paratonia, an apparent dyspraxia on walking and biliateral aquileus clonus. His speech was jerky and slurred, and he manifested a continuous and fatuous grin and cheerful disposition. He recognized people and was time and space oriented. The plasma ceruloplasmin level was $2 \mathrm{mg} / \mathrm{dL}$ (normal: 200 to 400 ), the serum copper wias $69 \wedge \mathrm{g} / \mathrm{dL}$ (normal: 70 to 140) and the $24 \mathrm{~h}$-urinary copper was 68.64 ^gj (normal: 0 to 40). A CT scan showed ventricular dilatation and hypodensities in the subcortical white matter of the left frontal lobe. D-penicilamine therapy was started but the patient failed to return to follow-up. Twelve months later, during which the family abandoned the treatment, he came back to our hospital. At the age of 17 years, he had become bedridden. He had difficulty in swallowing and his speech was unintelligible. He developed a pyramidal syndrome on right members and on the left side cogwheel rigidity was evident. Partial motor seizures on left extremities have appeared, corresponding to a focus on right temporo-frontal areas on EEG.

Another CT scan was done, that showed further structural deterioration (Fig. 1). The ventricular system and cisterns were more enlarged, and thalami were shrunken. The low densities on superior aspects of left frontal lobe became more evident. We restarted therapy with D-penicilamine, Ig/day, but no improvement was noticed until now.

\section{COMMENTS}

The most conspicuous pathologic change in WD is atrophy of the lenticular nucleus'^. The putamen and caudate can appear with severe degeneration and cavitation; at other times, they are soft and shrunken. There are further minor lesions in brainstem, in cerebral cortex and in cerebellum.

Destruction of the white matter of the cerebral hemispheres has been described on early anatomo-pathologic reports n.13. The more recent papers about CT scan on WD have mentioned lesions in basal ganglia, cerebellum and capsular regions associated with ventricular dilatation 6,7,9,12,15. The degenerative changes of white matter seen on pathological specimens were almost never seen on CT grounds, perhaps because nowadays the treated patients have not the same relentless course as the untreated ones. These white matter changes showed a predilection for the superior portions of the hemispheres, involving to the great extent the first and second frontal gyri 11. We think our patient has a CT picture consistent with Schulman and Barbeau report, except by the asymmetry of involvement presented here.

We were able to find only one case report showing low density areas in the subcortical white matter on CT scan, although it seems that at least one else exists ${ }^{14}$. 

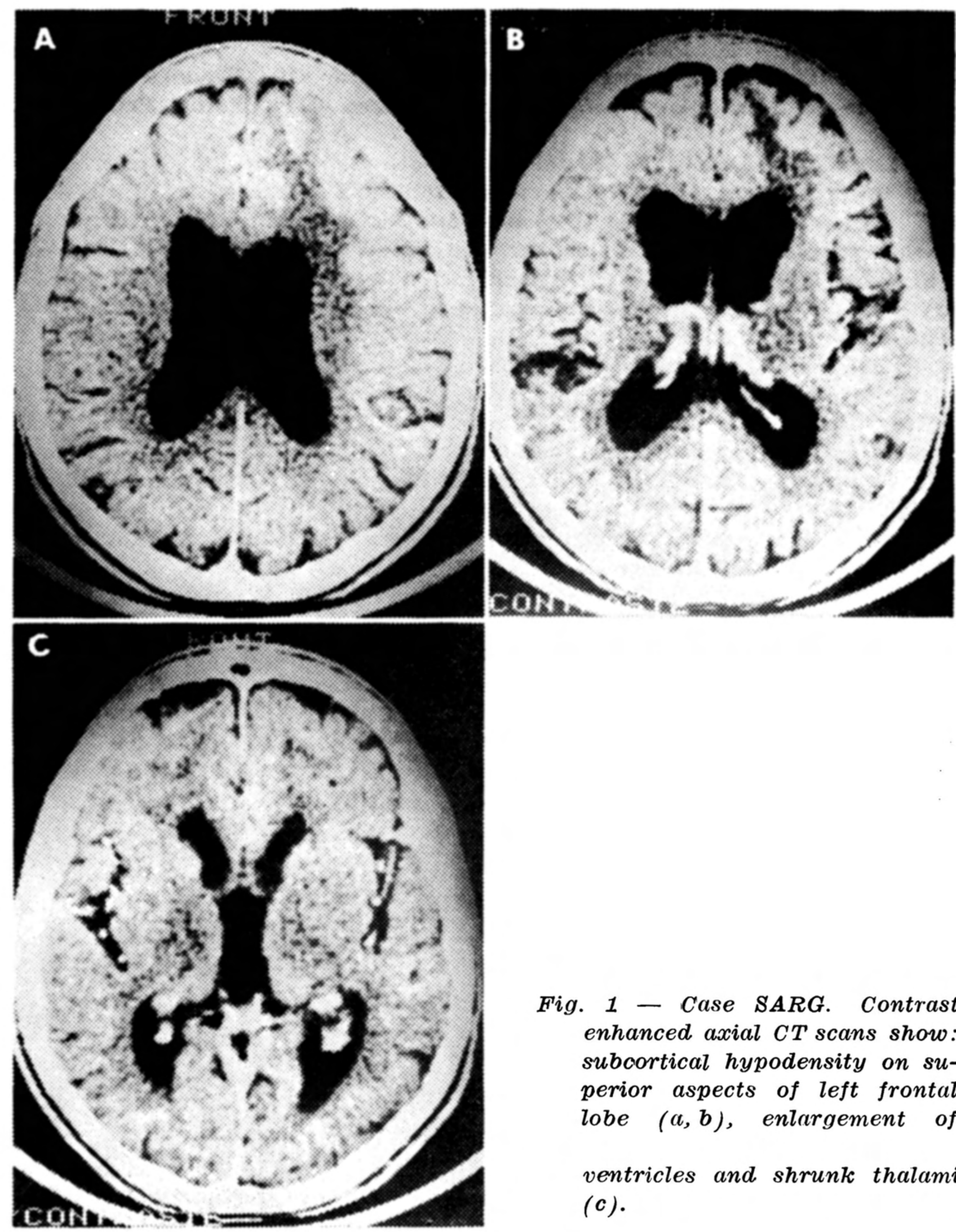

Fig. 1 - Case SARG. Contrast enhanced axial CT scans show: subcortical hypodensity on superior aspects of left frontal lobe $(a, b)$, enlargement of ventricles and shrunk thalami (c).

This rarity could change with the use of magnetic resonance imaging (MRI). StarostaRubinstein et al. ${ }^{13}$ found white matter lesions with some frequency on WD using MRI, but did not correlate these findings with neurologic status. Schulman and Barbeau thought that the cause for these unusual aspects was prolonged duration of the disease. We are tempted, however, to correlate our finding with the severity and unusually rapid downhill progression presented by our patient.

Acknowledgements - The Medical Genetics Unit is supported by grants of Brazilian research agencies (CNPq, FINER, FAFERGS and PROPESP/UFRGS) and RTMDC (Research Trust for Metabolic Disease in Children). R.G. is recipient of a research fellowship from CNPq.

\section{REFERENCES}

1. Barbosa ER, Scaff M, Comerlatti LR, Canelas HM. Hepatolenticular degeneration: a critical analysis of the diagnostic criteria on the, ground of 95 cases. Arq Neuro-Psiquiat (São Paulo) 1985, 43:234-242.

2. Berkow R. Wilson's disease in the Merck Manual: corrections (let). JAMA 1988, 258: 2997-2998. 
3. Canelas HM. Hepatolenticular degeneration: a comprehensive review apropos of 102 cases. Arq Neuro-Psiquiat (São Paulo) 1987, 45 : 197-212.

4. Danks DM. Disorders of copper transport. In Scriver CR, Beaudet AL, Sly WS, Valle D (eds): The Metabolic Basis of Inherited Disease. New York: McGraw-Hill, 1989, p 1411-1431.

5. Figus A, Lampis R, Devoto $M$, Ristaldi MS, Ideo A, de Virgilis S, Nurchi AM, Corrias A, Corda R, Lai ME, Tocco A, Deplano A, Solinas A, Zancan L, Lee WH, Cao A, Piᄀ rastu M, Balestrieri A. Carrier detection and early diagnosis of Wilson's disease by restriction fragment lenght polymorfism analysis. J Med Genet 1989, 26:78-82.

6. Harik SI, Post JD. Computed tomography in Wilson disease. Neurology 1981, 31 : 107-110.

7. McGrary JA. Magnetic resonance imaging diagnosis of hepatolenticular degeneration. Arch Ophtalmol 1987, 105:277.

8. McDowell FH, Lee JE, Sweet RD. Extrapyramidal disease. In Baker AB, Baker LH (eds): Clinical Neurology. Philadelphia: Harper and Row, 1982, chap 26, p 50-53.

9. Nelson RF, Guzman DA, Grahovac Z, Howse DCN. Computerized cranial tomography in Wilson disease. Neurology 1979, 29:866-868.

10. Saito T. Presenting symptoms and natural history of Wilson disease. Eur J Pediatr 1987, 146:281-265.

11. Schulman S, Barbeau A. Wilson's disease: a case with almost total loss of cerebnal white matter. J Neuropath Exp Neurol 1964, 22:105-119.

12. Selekler H, Kansu T, Zileli T. Computed tomography in Wilson's disease. Arch Neurol 1981, 38:727-728

13. Starosta-Rubinstein S, Young AB, Kluin K, Hill G, Aisen A, Gabrielsen T, Brewer GJ. Clinical assessment of 31 patients with Wilson's disease. Arch Neurol 1987, 44:365-370.

14. Takano K, Kuroiwa Y, Shimada Y, Mannen T, Toyokura Y. CT manifestation of cerebral white matter lesion in Wilson disease. Ann Neurol 1983, 13:108-109.

15. Williams FJB, Walshe JM. Wilson's disease: an analysis of the cranial computerized tomographic appearances found in 60 patients and the changes in response to treatment with chelating agents. Brain 1981, 104:735-754. 